\title{
Evaluation and Comparison of Three Open Courseware Based on Quality Criteria
}

\author{
Monica Vladoiu and Zoran Constantinescu \\ UPG University of Ploiesti, Romania \\ \{monica, zoran\} @unde.ro
}

\begin{abstract}
In spite of the scale, popularity, and importance of the open courseware movement for users worldwide, there is yet no quality assessment framework that could support users on their quest for finding the most appropriate learning resource with regard to their educational needs. This paper presents both an evaluation and a comparison between three open courseware on databases offered by three major open courseware providers, which comply with three different open courseware paradigms. Both evaluation and comparison are based on our set of quality criteria that serve as general guidelines for development, use, modification, evaluation, and comparison of open educational resources and open courseware, from a social and constructivist perspective.
\end{abstract}

Keywords: open courseware, quality criteria, open courseware on databases.

\section{Introduction}

During more than one decade, we have been witnessing a paradigm shift of education, training, and learning, which has been triggered by the demands and challenges of emerging knowledge economy and learning society. Learning is now a continuous process that is no longer limited to dedicated spaces, times or modalities, in which borders between providers and consumers of knowledge are blurred. Users, communities, social construction of knowledge, $21^{\text {st }}$ century's information and communication technologies, and open education models constitute the backbone of this paradigm shift that provide for lifelong and lifewide learning. Knowledge is more and more seen as public good that can be accessed, shared, used and reused, adapted etc.

Open courseware and open educational resources projects around the world have a significant contribution to this paradigm shift, as they open access to, otherwise closed, university-level educational materials. More than 10 years have passed since the launch of the MIT OpenCourseWare (OCW) program - now having more than 2100 courses online, which has triggered the emergence of numerous university programs that offer open access to some of their courses that have been developing in parallel with OCW: Stanford Engineering Everywhere, Carnegie Mellon Open Learning Initiative, Harvard's Open Learning Initiative and Harvard Medical School's MyCourses, Open Yale Courses, Webcast.Berkeley, Rice University's Connexions, Open University's OpenLearn, Open.Michigan, and so on. Besides these open courseware initiatives hosted by major universities, large open courseware reposito- 
ries are available as well: OpenCourseWare Consortium, Open Education Resources (OER) Commons, and The Saylor Foundation's Free Education Initiative $[1,2]$.

Despite the magnitude, pervasiveness, and impact of the open courseware movement, on users worldwide, there is yet no quality assessment framework that could provide support for users. Thus, learners need guidance for choosing the most appropriate educational resources that fulfills their educational needs, while instructors are interested in support for instructional activities, which provide for achievement of learning goals, objectives, and outcomes, along with reflective learning. Faculty or institutions that are or want to become involved in the open courseware movement may be interested in the challenges and rewards of this process. Though, there is preoccupation about articulating a set of criteria for quality assessment, which may be used to support construction, evaluation and comparison of open courseware and open educational resources and repositories. However, the related work is extremely thin, with just a few works approaching the general subject of quality of open courseware and OERs in the context of assessing the impact of these paradigms in education nowadays. All these works emphasize on the importance of the quality of OERs and OCW, and on the need for continuous quality evaluation and assurance [3-10]. Still, none of these works has attempted to elaborate a set of quality criteria to be used for quality evaluation and assurance.

In this paper we evaluate and compare quality-wise three open courseware on databases offered by three major open courseware providers that comply with three different open courseware paradigms. The comparison is guided by our set of socioconstructivist quality criteria that serve as general guidelines for development, use, modification, evaluation, and comparison of open courseware and OERs [11]. Moreover, this work attempts to work those quality criteria on the chosen open courseware, and to learn, based on this experience, how to develop further the initial set of quality criteria.

The structure of the paper is as follows: the second section presents briefly our set of quality criteria, the third one introduces the three "candidates" for comparison, the fourth presents the evaluation and comparison of the three open courseware based on the quality criteria, and the last consists of some conclusions and future work ideas.

\section{Criteria for Quality Assurance of OER and OCW}

In this section, we present briefly a set of criteria for quality assessment of open educational resources and open courseware that has been introduced and presented in more detail in [11]. They may be used for quality evaluation of either small learning units or an entire courseware. These criteria have been grouped in four categories related with content, instructional design, technology and courseware evaluation. They correspond to quality characteristics of quality in use, internal and external product quality according to ISO/IEC 25000 SQuaRE standard, and cover the following user needs: effectiveness, efficiency, satisfaction, reliability, security, context coverage, learnability, and accessibility.

Content Related. This category includes criteria that reveal to what degree the educational resource allows learners having engaging learning experiences that provide for 
mastery of the content, such as: readability, uniformity of language, terminology, and notations, availability of the course syllabus, comprehensiveness of the lecture notes, modularity of the course content, possibility to select the most suitable learning unit, opportunity to choose the most appropriate learning path, top-down, bottom-up or combined approach, and availability of assignments (with or without solutions).

When considering only a particular learning resource - a small learning unit, a course module, a lesson etc., users may be interested in various aspects related to that resource: accuracy, reasonableness, self-containedness, context, relevance, availability of multimedia inserts, and resource's correlation with the course in its entirety.

Instructional Design Related. Criteria refer to resource's goal and learning objectives, appropriate instructional activities, learning outcomes, availability of the evaluation and auto-evaluation means (with or without solutions), learning theory, the instructional design model used for that particular educational resource, and reflective learning proneness. Outcome of reflective education is the construction of coherent functional knowledge structures adaptable to further lifelong learning [12-15].

Technology Related. In this category we find aspects of compliance with standards for interoperability and accessibility, extensibility, reliability, user interface's navigational regard to the at user's end (both hardware and software), along with the prerequisite skills to use that technology, multi-platform capability, supporting tools, and security of user confidential information.

Courseware Evaluation. In spite of the original statement of just offering high quality educational materials to users around the world, with no further aim to support them during their educational journeys, all major open courseware initiatives have recently become more involved with their learners. Therefore, regular assessment of effectiveness of open courseware becomes crucial. Moreover, the results of the evaluation may be used for further improvements. First criterion to be considered here is the courseware overview, which includes information about the content scope and sequence, the intended audience, the grade level, the periodicity of updating the content, the author's credentials and the source credibility, its availability in multiplelanguages, instructor facilitation or some kind of semi-automated support, suitableness for self-study and/or classroom-based study and/or peer collaborative study, the time requirements, the grading policy, along with instructions about using the courseware and its components.

Other criteria included in this category are as follows: availability of prerequisite knowledge, availability of required competencies, matching the course schedule with learner's own pace, availability of repository or institutional policies, bias and advertising freeness, option to provide a formal degree or a certificate of completion, user interface, appropriate design, and suitable presentation of educational content. Some participatory culture and Web 2.0 facets are also relevant when evaluating the quality of open courseware: contribution to the content, collaboration with fellow users, collection of users' feedback, sharing the development or using experience. 


\section{Three Open Courseware on Databases}

In this section we provide a brief presentation of the three open courseware that offer educational materials on databases. We have chosen these particular educational resources because they are offered by three major open courseware providers, and because they comply with three different open courseware paradigms. The three candidates for quality evaluation and comparison are the MIT OpenCourseWare on Database Systems [16], The Saylor Foundation's Introduction to Modern Database Systems courseware [17], and Stanford's Introduction to Databases courseware [18].

\subsection{MIT OpenCourseWare on Database Systems}

MIT OpenCourseWare is a web-based free publication of virtually all MIT course content. OCW is open and available to the world and it is a permanent MIT activity. The course materials reflect almost all the undergraduate and graduate subjects taught at MIT. However, OCW does not stand for a formal MIT education, and it does not grant university degrees or certificates. Moreover, the course materials may not mirror the entire content of a course [16].

The Database Systems course is one of the 2100 MIT courses that have been made freely available via the MIT OCW site [19]. It is an introductory course on foundations of database systems that addresses to graduate students with no prior database experience. Courseware overview includes the course topics, the prerequisites, information about grading, and the course readings. While some of this information is of interest only for MIT students, other is also useful for MIT OCW users. Selected lecture notes, assignments without solutions, and exams with solutions are available too.

\subsection{The Saylor Foundation's Introduction to Modern Database Systems}

Saylor.org has been launched by The Saylor Foundation as a free online university. The saylor.org is seen as a zero-cost alternative to those who lack the resources to attend traditional brick-and-mortar institutions, and as a complement to mainstream education providers that will both motivate people around the world to pursue personal growth and career ambitions, and lead to institutional change amongst education providers [20]. The Foundation's goal is to offer to many individuals the opportunity to overcome the barriers of attending mainstream college education: fixed class schedule, physical distance to a campus, rising costs related to tuition, fee, and textbooks etc. For now, saylor.org offers appropriate content that a student needs to know in order to earn the equivalent of a degree in any of the top majors in the USA.

Introduction to Modern Database Systems is one of the 200 courses freely available at The Saylor Foundation site, which is mandatory for the Computer Science program [17]. This course provides students with an introduction to modern database systems. The courseware overview includes learning outcomes, course requirements, and learning units. Syllabus, readings, web media lectures, automated assessments and final exam are also available from the course home page. 


\subsection{Stanford's Introduction to Databases}

Stanford's Professor Jennifer Widom has taken the challenge of a "flipped classroom" and has made freely available the online version of the Introduction to Databases course. While courses at Stanford are normally videotaped for internal purposes, the challenge consisted of "purpose-building" better videos, which were shorter, topicspecific segments that were spiced with in-video quizzes that allowed learners to check their understanding. That approach would have made the class more attractive for students and instructors, providing for interactive activities, interesting topics, and guest speakers [21]. The online version of the Introduction to Databases course is the result of taking that challenge. Available courseware may be used either on learner's self pace, in a "self-serve" mode, or by sticking to the tight course schedule. Course materials and video lectures, automated assignments and exams, extra exercises, software quick guides, Q\&A Forum, and weekly "screenside" chats are offered.

\section{Comparison between Three Open Courseware on Databases}

This section includes an evaluation of each of the three open courseware on databases that have been presented in brief in the previous section. The three courseware have been evaluated based on the quality criteria introduced in [11], and presented here in a few words in Section 3. For the time being, the inspection procedure is informal and each criterion has been evaluated in a qualitative manner based on the evaluators' perspective and experience on teaching Databases for more than 20 years. A comparison between them follows the evaluation.

\subsection{MIT OCW on Database Systems vs. The Quality Criteria}

This section includes our quality evaluation based on the proposed quality criteria for the MIT OCW on Database Systems.

Content-Related. The readability of the course material is very different as the learning units have different authors. The selected lecture note available as .pdf files are the work of two instructors. One of them has written very telegraphic notes that are very valuable, of course, as the instructor is one of the most well-known names in databases (a true titan of the field), but they are very hard to read and comprehend for someone who has no previous knowledge of databases. The other, however, has provided textbook style lecture notes, which can be read and followed far more easily for inexperienced learners. The uniformity of the materials is also impaired by this dualism. The course syllabus for the course taught in Fall 2010 is offered. The courseware is modular and quite comprehensive with very few lecture notes unavailable, and providing both assignments (no solutions) and exams (with solutions). Selection of the most suitable learning unit and learning path can be done easily provided that the learner has previous familiarity with databases. The courseware may be approached 
top-down, bottom up or combined. Each instructional resource is accurate, reasonable, self-contained, relevant in the context of learning about databases, and correlated with the entire course. No multimedia inserts are provided. Only links to readings available on amazon.com are provided.

Instructional Design Related. The general instructional goal is presented in the course description. The course syllabus presents only the learning objectives and the learning outcomes of the entire course, there is no such offering for the learning units. The available instructional materials provide only for basic instructional activities. The only auto-evaluation or evaluation means are the exams of 2008, along with their solutions. Reflective learning has not been yet considered for this course. No information about learning theory or instructional design is given.

Technology Related. The courseware complies with interoperability standards. The web accessibility issues are detailed in the FAQ technology page of the OCW Help. However, a direct link to that page from the course page would be useful. Only the instructors may extend the instructional resources. The user interface is basic. Prerequisite skills of using the technology are not explicitly stated because they are, probably, considered too basic. The courseware may be used reliably on multi-platforms, and the technical requirements and supporting tools are described in Help FAQ Technology page. Privacy and Terms of Use page presents the issues of privacy and security of confidential information.

Courseware Evaluation. The content scope and sequence may be deduced from the Course Calendar page. The intended audience or grade level is explicitly affirmed in the course home page. No information about periodicity of updating is available. Authors' credentials and source credibility are, definitely, exceptionally high. No availability in multiple languages nor support for learners have been provided. The courseware may be used for self-study or classroom based study. Time requirements to cover the course materials are not available. Grading policy is presented, but it refers only to MIT students. Getting started section of the OCW Help provides instructions on "how to" use the courseware and its components.

The prerequisite knowledge and required competencies are revealed in the Syllabus page. The learners may use the courseware at their own pace, so there is no matching problem regarding the course schedule. Repository policies are presented in the Terms of Use page. The courseware is free of bias and advertising. For the time being, no degree or certificate of completion is obtainable. Learners may not contribute to the resources nor collaborate with fellow learners. Feedback from users may be given only via the Contact us form. Inside information about the OCW challenge and development journey, in general, are available in the About us page. No such information about the Database Systems courseware is given. The user interface, design and presentation of the instructional content are plain. 


\subsection{Saylor's Courseware on Database Systems vs. The Quality Criteria}

We present here our quality assessment based on the proposed quality criteria for Saylor's Courseware Introduction to Modern Database Systems.

Content-Related. The readability and uniformity of the course materials is quite different as the learning units have different authors. The content is a particular combination of HTML readings, web media lectures, assignments (quizzes and animations) that includes the final exam as well. The instructional materials may come from other institutions, collections or repositories, but there are also some in-house developed ones. They all have been selected, framed, and/or developed by our professors so that they will enable the achievement of the stated learning goal is said on saylor.org. The detailed course syllabus is available. The courseware is modular and very comprehensive as shown above. Assignments (with solutions) are offered. Selection of the most suitable learning unit and learning path can be done easily as the courseware is very intuitively built. The courseware may be approached top-down, bottom up or combined. Each instructional resource is accurate, reasonable, self-contained, relevant in the context of learning about databases, and correlated with the entire course. Multimedia inserts are provided. Only links to the course readings are available.

Instructional Design Related. The general instructional goal is presented both in the course syllabus and in the course home page. The learning objectives and outcomes are available at two levels: course-wide and learning unit-wide. Diverse instructional activities provide for meaningful learning experiences and stimulate reflective learning. Dynamic and animated auto-evaluation or evaluation means are accompanied by either answer keys, guides to responding, or self-assessment rubrics (a list of criteria that can be used to determine the quality of a work) so that learners themselves can evaluate their own work. Each time the final exam is taken learners are offered different questions. No information about learning theory or instructional design is given.

Technology Related. Interoperability standards are fulfilled by the courseware. Accessibility is approached only in its larger sense rather than as web accessibility. Only the instructors may extend the instructional resources. The user interface is advanced and appropriate. The Saylor Student Handbook includes the supporting technical requirements, along with some prerequisite skills of using the technology. The courseware may be used reliably on multi-platforms, and the supporting tools are described in the handbook as well. Terms of Use page shows the issues of privacy and security of confidential information.

Courseware Evaluation. Starts with courseware overview. The content scope and sequence are presented in the course syllabus and course home page alike. Course audience and grade level is explicitly approached, but on saylor.org home page not on the database course's one. No information about periodicity of updating is on hand. For some learning units author's credentials are obvious, as they are professors at 
prestigious universities, while for others learners have to rely on source credibility, which is considerable in our opinion. The instructional resources are available in English only. The support for learners is semi-automated, being visible mainly on assignments. For now, the courseware may be used for self-study and classroom based study, but, taking into consideration the latest developments (forums, e-portfolios etc.), it seems that peer collaborative study is envisaged as well. Both syllabus and home page provide a time advisory, which show the needed time to complete each instructional resource. Student handbook details the grading policy and instructions on "how to" use the courseware and its components. The prerequisite knowledge and required competencies are presented in the course home page. Learners may use the courseware at their own pace.

Student Handbook includes also the community standards, i. e. the repository policies, along with the statement regarding the freeness of bias. The courseware is free of advertising as well. After passing the exam with more than $70 \%$, the student is provided with a certificate of completion having a unique identification code. For the time being, learners may not contribute directly to the resources or collaborate with fellow learners. However, they may submit materials that might get chosen to be published on the saylor.org website. Feedback from users is collected via a user survey. Some hints about the development journey and saylor.org experience are presented in the student handbook as well. The user interface, design and presentation of the instructional content are well elaborated and attractive.

\subsection{Stanford's Introduction to Databases vs. The Quality Criteria}

We detail here our assessment of the open courseware of Introduction to Databases course of Stanford's Professor Jennifer Widom, against the proposed quality criteria.

Content-Related. The text materials that are available in two formats, namely .pdf and .pptx, are easy readable and very uniform in terms of language, terminology and notations, as they have a unique author. The course syllabus is not presented as such, but all the needed information is offered in the course home page. As for the comprehensiveness of the lecture notes, they do not include the Entity-Relationship approach for database design, being focused only on database normalization theory. Otherwise, plenty of quizzes, assignments, extra-exercises, demo scripts, quick-guides for relevant software, pointers to textbook readings, and other course materials, are on hand to be used for strengthening the learning process. As the online courseware has been designed from the very beginning as modular, the selection of the most suitable learning unit or learning path is straightforward. The course materials may be approached easily top-down, bottom-up, or in a combined way. The assignments are available without solutions. Professor Widom motivates this with the difficulty to construct so many meaningful assignments annually for each learner cohort. Each instructional resource is accurate, reasonable, self-contained, relevant in the context of learning about databases, and correlated with the entire course. Multimedia inserts are provided. No links to related resources are offered, only a list of textbooks. 
Instructional Design Related. The general instructional goal is stated in the home page, but the learning objectives and the learning outcomes are not declared explicitly for the entire courseware nor for the learning units. They can be deduced, however, from the course syllabus. The educational materials provide for engaging multiple instructional activities, hence for rich opportunities for learning. They include: video lectures, in-video quizzes, course materials, and self-guided exercises, i.e. quizzes that generate different combinations of correct and incorrect answers each time they're launched, and interactive workbenches for topics ranging from XML DTD validation to view-update triggers $[18,21]$. To auto-evaluate their learning progress learners may use automated assignments, both quizzes and exercises. Automated exams are available for evaluation. In our opinion, the courseware seeds the stimuli for reflective learning, especially due to Professor Widom's commitment and personal touch, and to the vibrant collaboration on the Q\&A Forum. Moreover, to prevent rapid-fire guessing, the system enforces a minimum of ten minutes between each submission of solutions, so learners have some time to reflect. No information about learning theory or instructional design model is available.

Technology Related. The courseware complies with interoperability standards, and people with accessibility issues are invited to contact the support team on the last line of the About us page. Maybe a more visible invitation would be more practical. Instructional resources may be extended only by the members of the team. The user interface is basic. The supporting technology requirements at user's end are not available. Prerequisite skills of using the technology are not offered as they are probably considered to basic to mention. The courseware may be used reliably on various platforms, and the supporting tools are described in Software Quick Guides. The issues of security of confidential information are approached in the Terms of Service page.

Courseware Evaluation. Courseware overview criteria are considered further on. The content scope and sequence are deducible from the Course Schedule. No intended audience or grade level is explicitly affirmed. Despite the initial claim that it will not be a second database course offered in the immediate future, currently on the home page we learn that the next official offering will be likely in the latter part of 2012 - most probably then some content updating will be available as well. Author's credentials and source credibility are, of course, extremely high. The courseware is not available in any other language than English, however it has attracted students from 130 countries, top three being USA, India, and Russia. Support for learners is provided by instructor only by discussing during the weekly video the top unanswered questions on the Q\&A forum. Some semi-automated support exists as well based on quizzes with Gradiance-style grading. Thus, after submitting a selection the system will score the quiz, and for incorrect answers will provide an "explanation" (sometimes for correct ones too), which is supposed to help learners get the right answer the next time around. Moreover, learners get a different variant of each problem of the quizzes on every attempt, so they are advised to continue taking them to reinforce their understanding, even after they have achieved a perfect score on one variant. 
The courseware is suitable for self-study, classroom based study, and peer collaborative study. No time requirements to cover the course materials are available. However, in no "self-serve" mode, the time schedule was very tight, and the learners have been constantly struggling to meet the deadlines. FAQ page presents the grading policy and instructions on "how to" use the courseware and its components. Multiple-choice midterm and final exams are crafted carefully so that the problems are not solvable by just running queries or checking Wikipedia. Creating these exams, at just the right level, turned out to be one of the most challenging tasks of the entire endeavor, Professor Widom says.

The prerequisite knowledge and required competencies are shown in the FAQ page. The learners are allowed to use the courseware at their own pace, but the ones choosing that approach were not allowed to get the statement of accomplishment offered by Professor Widom. Terms of Service state the repository policies to comply with. The courseware is free of bias and advertising. Learners may not contribute to the resources. However, they may collaborate with fellow learners. Feedback from users is collected to be used for future improved versions. Professor Widom tells the story of the development journey and the whole experience in a very touching way on her ACM SIGMOD blog [21]. The user interface, design and presentation of the instructional content are basic.

\subsection{Comparison of the Three Open Courseware Based on the Quality Criteria}

We present here a comparison of the three open courseware that have been evaluated in the previous sub-sections. During this section, to make the exposition easier, we will be using three acronyms for the three open courseware: MITOCWDB, SaylorDB and StanfordWidomDB.

As a general idea, the most beneficial for learners in this moment is, in our opinion, StanfordWidomDB due to the commitment and enthusiasm of Professor Widom and her team. Saylor people are also very committed to the idea of offering valuable meaningful experiences, but what has made the difference between the two of them is, in our view, the fact that Professor Widom has involved herself personally (along with the team, of course) in the process, she has been keeping in touch with the learners, and she has confessed having "a grand time"[21], despite the challenges. MITOCWDB, despite the quality of the instructors and materials, lacks the direct connection with and support for its users.

However, both StanfordWidomDB and SaylorDB provide for engaging, reflective learning, based on personal touch only for the former, and on the powerful learning experiences triggered by the well designed instructional materials for both of them. Moreover, both open courseware have considered offering some sort of certificate of completion. Related to that, they have addressed also the cheating issues.

The user interface and supporting framework looks best in SaylorDB due, in our view, to the fact that Saylor.org is thought to become an open online university, where independent learners are ought to return with pleasure and confidence that the courseware materials are connected to them in a meaningful, unique, transformative way [20]. The main merit of MITOCWDB is that offers content provided by very 
high quality Professors, and, in a larger view, that with the OCW movement has started everything. Without it, the other "candidates" would have probably not existed. We conclude this section hoping that having many open courseware available, the struggle for quality will be encouraged for users' benefit, being them learners, instructors, faculty, developers, and even educational institutions.

\section{$5 \quad$ Conclusions and Future Work}

The main contribution of this paper consists in evaluating and comparing three open courseware on databases, using a set of quality criteria introduced in an earlier work. The three courseware have been chosen because they come from three major open courseware providers, and they comply with three significantly different open courseware paradigms. This work has tried to put into practice those quality criteria, and to learn from this experience how to develop further the initial quality model.

First thing learned is that there is no preoccupation yet for considering explicitly learning theories or instructional design models. Furthermore, new quality criteria have proven to be necessary. They include: support for learners coming from other learners, opportunity for peer collaborative learning, availability of quick guides of relevant software, and providing links to related relevant resources. Some criteria need to be extended. For example, accessibility needs to be seen at a higher level, not only as web accessibility, but as concerning access to as many people as possible to the open educational content. Security of confidential information has to be included in a larger subset of criteria regarding the terms of use (or service) for the open courseware that include: copyright and licensing issues, anonymity, age restrictions, netiquette, updating or deleting personally identifiable information, security for primary, secondary and indirect users in terms of ISO/IEC 25000 SQuaRE etc.

The quality criteria presented here, which may result in a quality model for open courseware and open educational resources, need significant future improvements. First they have to comply with existing quality standards (such as ISO/IEC 25000 SQuaRE standard), educational theories and best practice in the field. Each measurable criterion has to be evaluated in a quantifiable way, by devising an appropriate scoring or rubric system that will help "measuring" open courseware, helping this way both users and other evaluators to use the model. Moreover, the inspection procedure for quality evaluation and comparison needs to be taken to the next, more formal, level, aiming at providing a quality evaluation framework. Thus, learners and instructors may be provided with a valuable instrument for choosing the most suitable educational resource, and the learning path that fulfills their educational goals. In addition, developers may also use that framework to tailor their work.

Acknowledgements. The author is very grateful to the anonymous reviewers for their valuable comments and ideas to improve both the paper and the quality model. 


\section{References}

1. Vladoiu, M.: State-of-the-Art in Open Courseware Initiatives Worldwide. Informatics in Education 10(2), 271-294 (2011)

2. Vladoiu, M.: Open Courseware Initiatives - After 10 Years. In: 10th International Conference Romanian Educational Network - RoEduNet, pp. 183-188. IEEE Press, Iasi (2011)

3. OTTER - Open, Transferable, and Technology-enabled Educational Resources, http: / /www2 . le.ac.uk/departments/beyond-distance-researchalliance/projects/otter/about-oers/Corre-web.pdf/view

4. OpenCourseWare in the European HE Context, http: / / opencourseware. eu/workpackages /wp2

5. JISC Quality Consideration, https: //openeducationalresources.pbworks.com/w/page/ 24838164 / Quality+considerations

6. Schuwer, R., Wilson, T., Van Valkenburg, W., Lane, A.: Production of OER, a Quest for Efficiency. In: 7th Annual Open Education Conference, Open Ed 2010. UOC, OU, BYU, Barcelona (2010), http: / / hdl . handle.net/10609/5103

7. Blackall, L.: Open Educational Resources and Practices. Teaching English as a Second Language 11(4), 1-19 (2008), http: / /www. tesl-ej . org/ej44/a8 .pdf

8. Schaffert, S.: Strategic Integration of Open Educational Resources in Higher Education. Objectives, Case Studies, and the Impact of Web 2.0 on Universities. In: Ehlers, U.D., Schneckenberg, D. (eds.) Changing Cultures in Higher Education - Moving Ahead to Future Learning. Springer, New York (2010)

9. Fleming, C., Massey, M.: JORUM Open Educational Resources Report (2007)

10. Vest, C.M.: Open content and the emerging global meta-university. EDUCAUSE Review 41(3), 18-30 (2006),

http: / /www. educause. edu/apps / er / erm06/erm0630. asp?bhcp=1

11. Vladoiu, M.: Quality Criteria for Open Educational Resources and Open Courseware (submitted for publication)

12. Brockbank, A., McGill, I.: Facilitating Reflective Learning in Higher Education. SRHE and Open University Press Imprint (1998)

13. Light, G., Cox, R.: Learning and Teaching in Higher Education. The reflective professional. Paul Chapman Publishing (2001)

14. Loughran, J.J.: Developing reflective practice. In: Learning about Teaching and Learning through Modelling. Falmer Press (1996)

15. Schunk, D.H., Zimmerman, B.J.: Self-regulated learning - from teaching to self-reflective practice. Guilford Press (1998)

16. MIT OCW Database Systems, http://ocw.mit.edu/courses/electrical-engineering-andcomputer-science/6-830-database-systems-fall-2010/index.html

17. Saylor-Introduction to Modern Database Systems, http: / / www. saylor.org/courses/cs403/

18. Introduction to Databases, http://www. db-class . org

19. MIT OpenCourseWare, http://ocw.mit.edu

20. The Saylor Foundation, http: / /www . saylor.org

21. Jennifer's Widom SIGMOD Blog - From 100 students to 100,000, http: / /wp. sigmod. org / ?p=165 